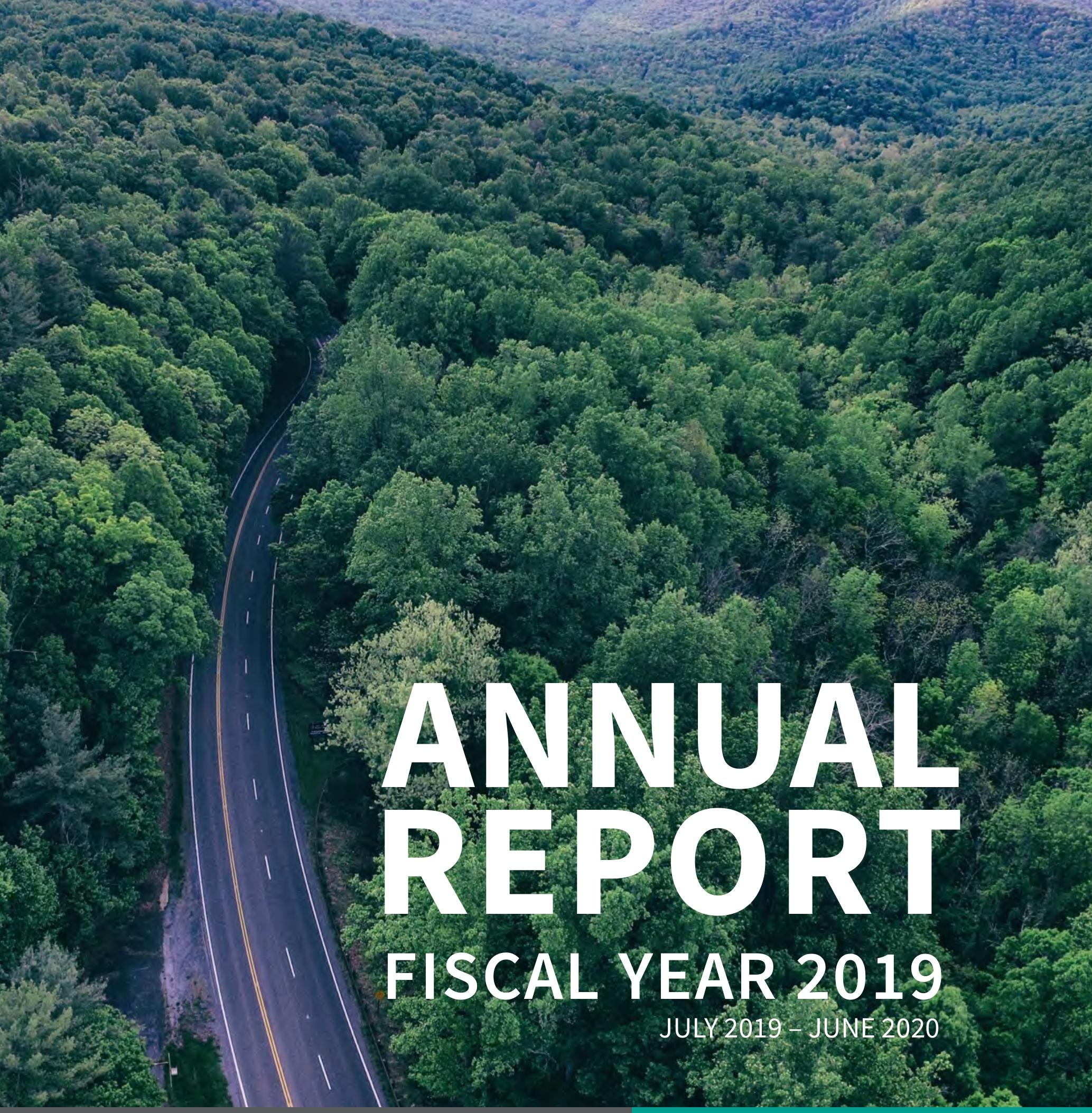




\section{About APN}

The Asia-Pacific Network for Global Change Research (APN) is an intergovernmental network of 22 countries working towards an Asia-Pacific region that is successfully addressing the challenges of global change and sustainability.

\section{Fiscal year 2019 at a glance}

\section{Member country involvement}

Project leaders and collaborators involved in APN programmes, aggregated by programme and nationality.

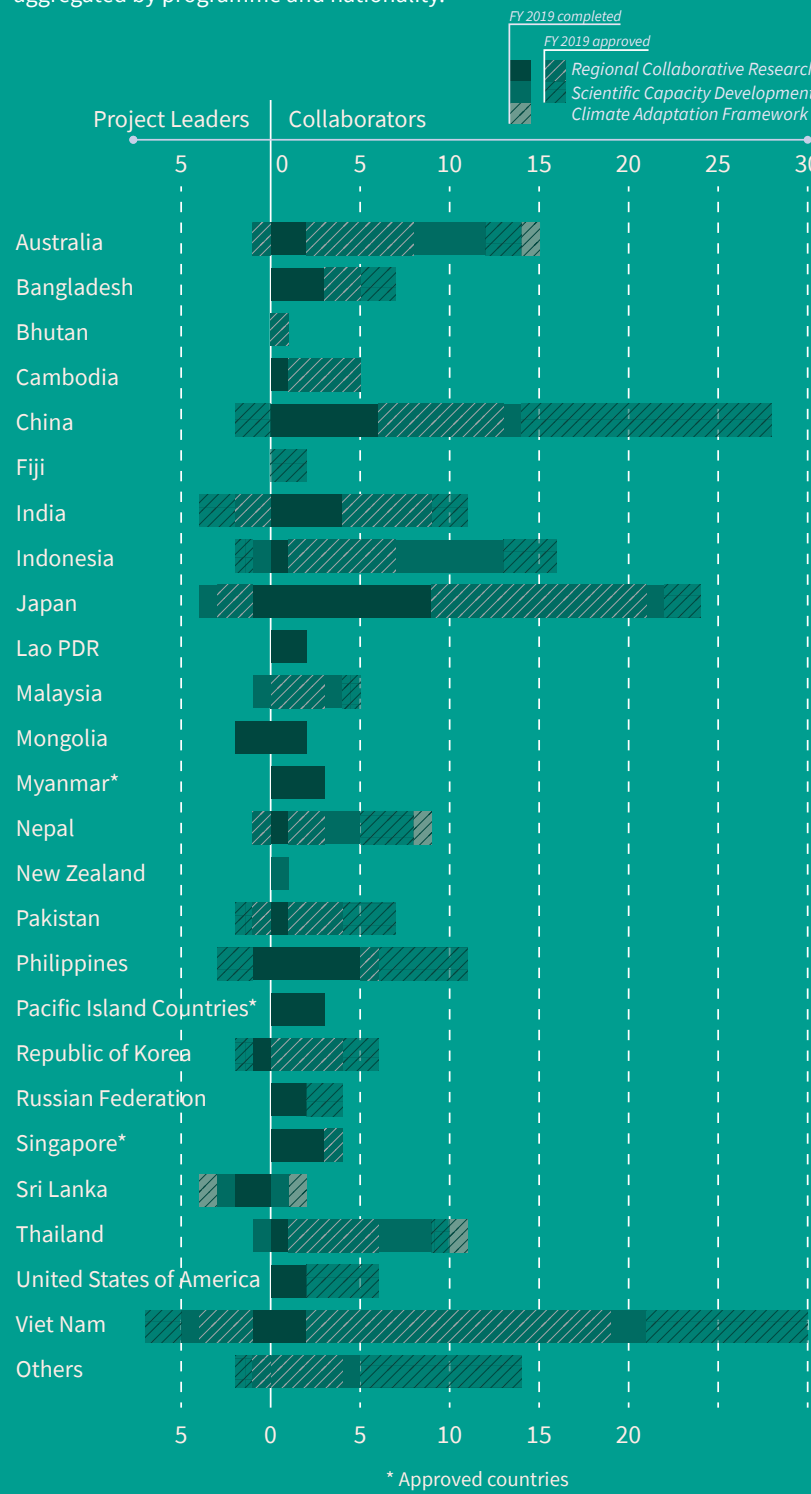

To achieve its mission, a set of programmes and activities are conducted.

$\checkmark$ Funds regional, multi-country and transdisciplinary research projects on global change and sustainability that provides underpinning scientific input to policymaking.

Funds and implements projects and workshops to develop the capacity of individuals and organizations to conduct high quality research on global change and sustainability.

Fosters and strengthens interactions between the science and policymaking communities to produce actionable science and informed decision-making.

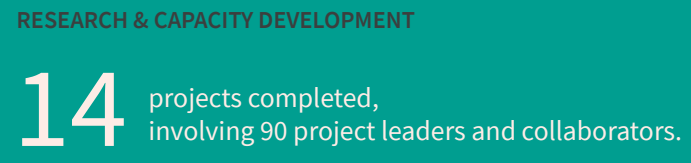

EXTENSIVE NETWOR

\section{$5,800+$}

researchers, government officials, community members and practitioners directly involved in projects.
4,008

active subscribers to the APN mailing list.
INVOLVING YOUNG SCIENTISTS

\section{$290+$}

early-career scientists directly involved in projects.

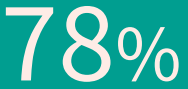

of projects reported involvement of early-career scientists.

\section{KNOWLEDGE MANAGEMENT}

\section{4 \\ 25,981}

publications produced and shared through the APN E-Library.

page views on the APN E-Library. 


\section{Climate}

\section{Identifying gaps and needs for implementing climate actions in Bangladesh, Nepal and Sri Lanka}

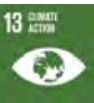

nationally determined Contributions (NDCs) are a key component of a country's climate action where the adaptation component plays an important role in countries that are particularly vulnerable to climate change. To identify and assess existing policy gaps and needs for the implementation of NDCs, the project conducted multi-stakeholder consultations, workshops, expert interviews and desktop research focusing on adaptation, and loss and damage in Bangladesh, Nepal and Sri Lanka.

The activities covered a broad spectrum of sectors from health and food security to human settlement and tourism, and identified gaps and needs in different areas such as policy, gender, financing as well as measurement, reporting and verification. Subsequently, the project produced three country analysis reports, one regional report and five policy briefs based on inputs gathered.

\section{Three country gaps and needs} analysis reports for Bangladesh, Nepal and Sri Lanka, one regional report, five policy briefs and six articles were developed and shared on a knowledge portal.

The outputs were compiled as a web-based knowledge portal (available at https://www.slycantrust.org/knowledge-portal/home) that was launched at the 25th session of the Conference of Parties

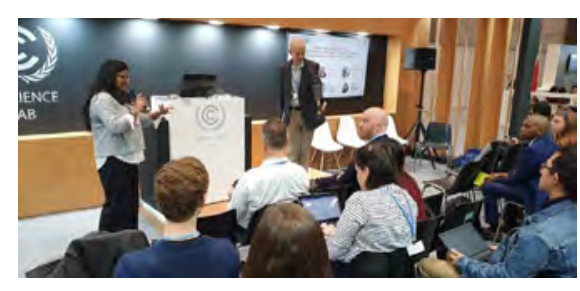

of the United Nations Framework Convention on Climate Change (UNFCCC). Additionally, the project conducted five webinars to share project results focusing on policy, governance, gender and the legal aspects of NDCs.
PROJECT Policy gaps and needs analysis for the implementation of NDCs on adaptation, and loss and damage in Bangladesh, Nepal and Sri Lanka PROGRAMME Collaborative Regional Research Programme (CRRP) PROJECT LEADER Ms Vositha Wijenayake, SLYCAN Trust, Sri Lanka ORGANIZATIONS INVOLVED Prakriti Resources Centre, Nepal; Independent University, Bangladesh WEBSITE https://www.apn-gcr. $\operatorname{org} / \mathrm{p}=3980$

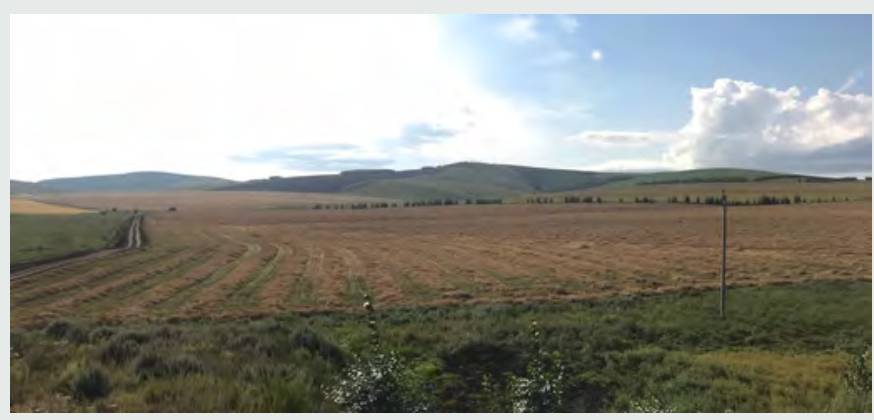

4 Assessments on ecological vulnerability conducted in western Mongolia revealed rapid expansion of degraded pastureland due to climate and human impacts. Subsequently, local government officials and herding groups increased their awareness of the linkages between socio-ecological governance and climate change adaptation. 


\section{Air, land, coasts and oceans}

\section{First regional assessment of water pollution impacts on carbon fluxes in Asian rivers}
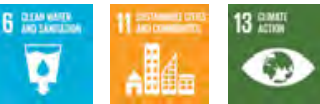

INLAND WATERS play an important role in the global carbon cycle, including carbon storage, atmospheric $\mathrm{CO}_{2}$ exchange and riverine carbon transport. However, the amount and fate of anthropogenic carbon in inland waters remain uncertain, and little is known about the characteristics and cascading effects of carbon contained in sewage and urban nonpoint source runoff.

To contribute to a better understanding of water pollution impacts on riverine GHG emissions, the project established a research network with a focus on the Mekong, Ganges-Brahmaputra and Yellow River basins, three large rivers originating from the water tower of Asia, the Tibetan Plateau.

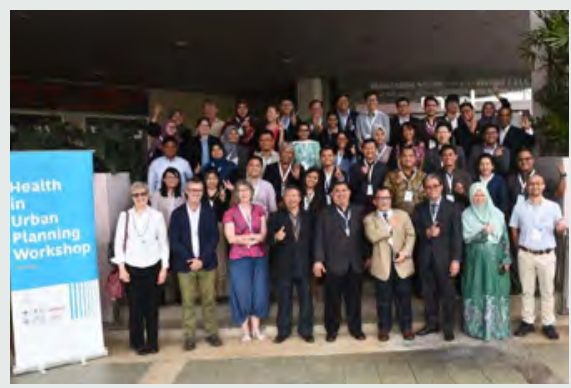

Subsequently, based on regional-scale estimates of riverine GHG emissions using new and standardized field measurements combined with literature and local monitoring data, the project found that riverine $\mathrm{CO}_{2}$ emissions in Asia

The project produced specific recommendations for alternative water policies integrating water quality control and climate change mitigation.

far exceed previous estimations. Additionally, the project found that rivers and tributaries located downstream of metropolitan areas represent "hotspots" of riverine GHG emissions.

Based on the findings, the project produced recommendations on alternative water policies that combine water quality control and climate change mitigation. The project also produced policy recommendations based on the specific needs of local and regional water agencies. Furthermore, it is hoped that the information on identified "hotspots" will assist these agencies to set priorities for alternative water policies.

PROJECT Water pollution impacts on
carbon export and greenhouse gas evasion
from Asian river systems PROGRAMME
Collaborative Regional Research Programme
(CRRP) PROJECT LEADER Dr Park Ji-Hyung,
Ewha Womans University, Republic of Korea
ORGANIZATIONS INVOLVED Royal University
of Phnom Penh, Cambodia; University
of Washington, USA; Physical Research
Laboratory, India; National University of
Singapore, Singapore; University of Hong Kong,
China; National Institute of Oceanography,
India; Jahangirnagar University, Bangladesh;
Cantho University, Viet Nam; Inner Mongolia
University, China WEBSITE https://www.
apn-gcr.org/?p=4552

1 Local and international researchers, policymakers and practitioners from Southeast Asia enhanced their awareness on the integration of public health issues, including air pollution, injury, physical inactivity, heat, noise and mental illness, into urban planning.

PROJECTLEADER Dr Soo Chen Kwan, Kyoto University, Japan WEBSITE https://www.apn-gcr.org/?p=4596 


\section{Biodiversity and ecosystems}

\section{Framework contributes to mangrove rehabilitation for local livelihood and community wellbeing}

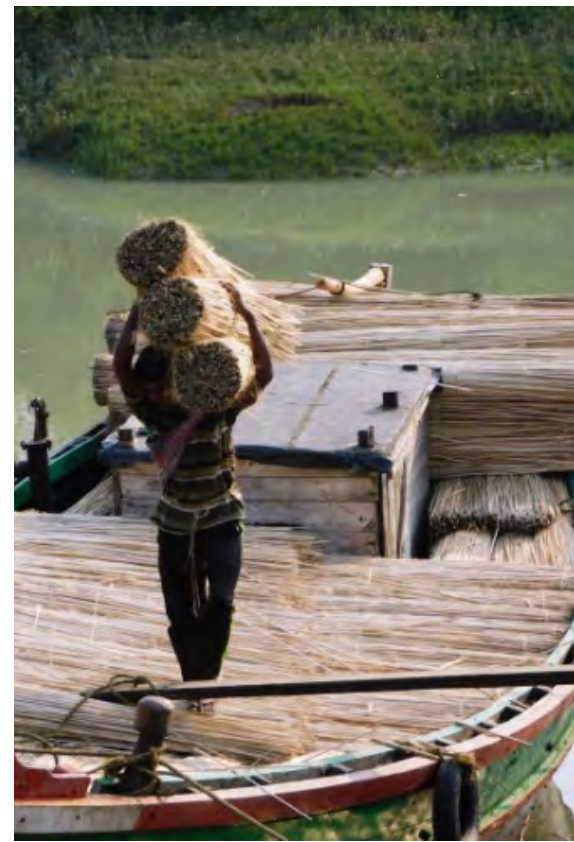

\section{MANGROVES OFFER MULTIPLE} services that enhance the lives and resilience of local communities. They also play a significant role in climate adaptation and mitigation. However, rehabilitation and management of mangroves continue to be a challenge in Asia.

The project conducted research in China, India, Japan, Myanmar and the Philippines, and identified critical issues in mangrove rehabilitation and management that include: low survival rate due to lack of knowledge on site-specificity of species; conversion to agriculture and aquaculture; insufficient incentives in local communities; inadequate labour resources; policy gaps in feasibility assessment, monitoring and enforcement; lack of studies on mangrove degradation; and soil runoff due to unsustainable agriculture practices.

The project promoted community-

based mangrove rehabilitation

approaches, and improved the capacity and skills of governments and other practitioners in mangrove rehabilitation.

To address these issues, the project created a framework for participatory mangrove rehabilitation, which details a holistic process that ensures all stakeholders have a shared vision and clear understanding of roles and responsibilities. The framework was tested in selected sites in Myanmar and the Philippines.

Consequently, the insights and lessons learnt from these test sites suggest that mutual understanding among stakeholders and community participation in planning and monitoring are foundations to the success of mangrove rehabilitation. Additionally, the project confirmed that for community-based approaches to be effective, collaboration and commitment are crucial, and that all stakeholders should equally benefit from the services that mangroves provide.

\footnotetext{
PROJECT Sustainable mangrove rehabilitation for global and local benefits PROGRAMME Collaborative Regional Research Programme (CRRP) PROJECT LEADER Dr Leni D. Camacho, University of the Philippines Los Baños, Philippines ORGANIZATIONS INVOLVED Forest Research Institute, Myanmar; Jawaharlal Nehru University, India; United Nations University Institute for the Advanced Study of Sustainability WEBSITE https://www.apn-gcr.org/?p=4570
}

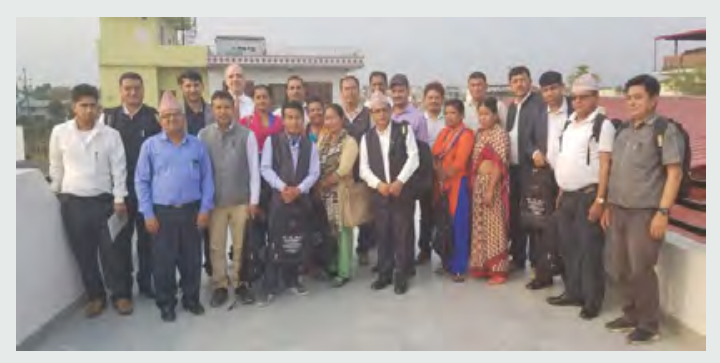

$\checkmark$ Over 100 professionals, government officials and community forestry staff in Nepal were trained on integrating climate action in community forest governance, and strengthening forest sector governance and inter-sectoral coordination for the effective implementation of REDD+ and other forest sector programmes in line with the country's NDCs.

PROJECT LEADER Dr Federico Lopez-Casero, Institute for Global Environmental Strategies, Japan WEBSITIE https://www.apn-gcr.org/?p=4597 


\section{Food, water and energy}

\section{Innovative online platform assists agriculture officers and farmers in combatting climate change}

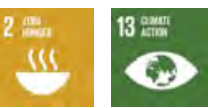

INDONESIA is a country with abundant and fertile soil, where agriculture is one of the major sectors contributing to the country's economy. However, recent changes in weather, pest attacks, and increased production cost has pushed rice farmers to quit farming for a living.

To increase the competencies in predictive skill and the improvement of plantation productivity among agriculture officers and farmers, the project developed a web-based interactive media platform called "Saung Iklim". The platform addresses the multi-dimensional complexity of the agriculture system in consideration of climate, economics and technology. This has enabled agriculture officers to work with farmers to implement smart climate actions and practical farming management based on climate information, such as specific and localized climate characteristics and estimation of crop production under various extreme climate conditions.

Additionally, the project produced a promotional video and an experimental demonstration plot to assist agriculture officers and farmers in the Subang Regency District to understand the challenges of farming better and to explore best practices in water supply, pest control, plant disease and suppression of plant growth due
The project developed five training modules to enhance the capacity of agricultural extension workers and farmer associations to understand the impacts of climate variability and climate change on rice productivity.

to pesticides. It is hoped that the promotional video and the experimental demonstration plot will be developed further to cater to other regions in Indonesia.

PROJECT Climate smart actions "Saung Iklim" for smallholder farmers in Subang District, West Java, Indonesia PROGRAMME Scientific Capacity Development (CAPaBLE) PROJECT LEADER Dr Perdinan, Bogor Agricultural University, Indonesia ORGANIZATIONS INVOLVED Bogor Agricultural University, Indonesia; Regional Development Planning and Growth Agency for Subang Regency, Indonesia; Agricultural Agency of Subang District, Indonesia WEBSITE https:// www.apn-gcr.org/?p=4599

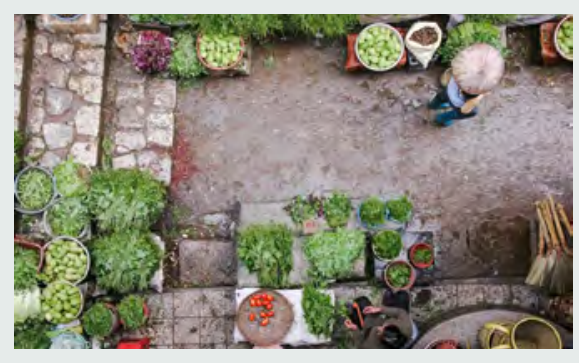

1 Studies on food safety risks of vegetables among consumers in Lao PDR, Cambodia and Viet Nam, revealed that risk perception is influenced by gender, knowledge on food risks and hazards, knowledge on the importance of vegetables, trust in institutions, and the presence of homegrown vegetables. 


\section{Risk and resilience}

\section{New model and guideline manages flood disaster risk in agricultural countries in Asia}

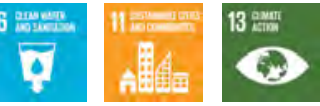

UNDER THE CURRENT TREND of natural disasters with increased impacts due to climate change, there is a need to develop and strengthen mitigation measures in vulnerable countries. The project developed a model to enlighten stakeholders on loss and damage associated with disasters in agriculture-dependent countries that suffer from annual flood disasters.

The project conducted a survey on the impacts of flood in agricultural production and how farmers cope with losses due to flood damage at 1,400 households in Nepal, Thailand and Sri Lanka. Based on the survey results, the project developed climate scenarios and trained 20 local government officials on how to use these scenarios.

Additionally, the project designed a guidebook to assist local government officials in developing plans to mainstream climate-smart disaster reduction and climate change adaptation practices in agricultural sectors. The guidebook also recommended the use of science-based solutions to assist local farmers in readjusting the cropping calendar and crop varieties
A practitioner's guidebook was published to help local government officials mainstream climatesmart disaster risk reduction and adaptation practices in the agriculture sector.

to minimize disaster risk.

The climate modelling results can be further refined using the new CMIP6 models and the results of the IPCC AR6, which are due in 2022.

PROJECT Developing climate inclusive potential loss and damage assessment methodology for flood hazards PROGRAMME Collaborative Regional Research Programme (CRRP) PROJECT LEADER Dr Senaka Basnayake, Asian Disaster Preparedness Center, Thailand ORGANIZATIONS INVOLVED The Small Earth Nepal, Nepal; Department of Meteorology, Sri Lanka; Deakin University, Australia WEBSITE https://www. apn-gcr.org/?p=4513
Special issue of Environmental Research takes stock of APN-funded climate-related activities, offering insights for adaptation planning

ASIA IS ONE OF THE MOST highly vulnerable regions in the world facing climate impacts due to its high population growth, diverse and varying geographical features, land use changes, and socio-economic factors such as poverty, industrial development, resource overuse, etc. It is crucial for countries to correctly understand these impacts and develop policies for adaptation and mitigation. For this, new knowledge on climate information, policy gaps and lessons learned are important, and should be widely disseminated among policymakers, practitioners and other relevant stakeholders.

Based on this understanding, APN and the Asian Institute of Technology (AIT) jointly organized a symposium and subsequently published a special issue titled "Climate Change Impacts, Vulnerability and Adaptation: Asian Perspective" in the journal of Environmental Research in July 2020. The publication consists of 14 articles that highlight findings of APN funded projects on climate change projections, climate impacts

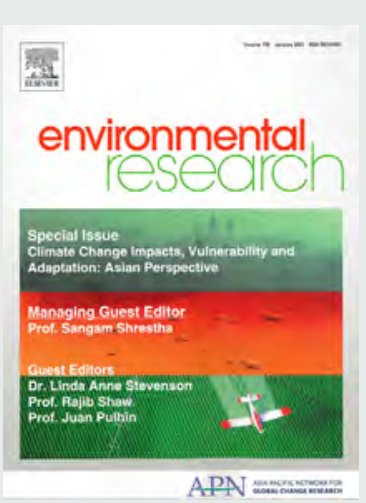

on health, water security, and building resilience of local governments, communities and micro business. The publication also includes a knowledge synthesis of climate change research in Asia. It is hoped that the publication will contribute to the existing efforts on climate assessment conducted by the Intergovernmental Panel for Climate Change (IPCC). 


\section{Scientific capacity development}

\section{Indigenous knowledge enhances community resilience to climate change}

Resilience in the face of change is embedded in Indigenous Knowledge (IK). However, the capacities of researchers, local communities, civil society organizations and the local government to generate evidence from IK, and to combine IK and scientific knowledge to make decisions and policies are limited in the mountainous region of Viet Nam.

The project organized a series of workshops to increase the capacity of stakeholders to conduct research on IK and to use research results to develop climate change resilience agricultural practices. Additionally, the project conducted a research on $\mathrm{IK}$ and climate change adaptation, in which research results were used to create training materials for local government officials and communities, learning materials for university students and writing manuscripts for publication. The project tested three resilient practices based on IK, which are the black-boned chicken raising model, the local green mung bean model, and local banana intercropping with medicinal plants, at 12 households to prove its resilience to climate change. Furthermore, the project provided technical training on bio-safe chicken raising, disease management for chickens, and banana care and microbiological composting techniques at 85 households.

Based on the findings, the project published a book titled "Using indigenous knowledge in agroecological and climate change resilience practices" and developed one policy brief, one leaflet and five posters to disseminate the project results. Consequently, the project increased the capacity of approximately 120 early-career researchers and 680 local people. Furthermore, the effectiveness of IK was recognized by the government, and is being used to develop climate change adaptation plans and programmes.

PROJECT Using indigenous knowledge to enhance community resilience to climate change in the mountainous region of Viet Nam PROGRAMME Scientific Capacity Development (CAPaBLE) PROJECT LEADER Mr Ho Ngoc Son, Agriculture and Forestry Research and Development Center for Mountainous Region, Viet Nam ORGANIZATIONS INVOLVED Vietnam National University, Hanoi, Viet Nam; Thai Nguyen University of Agriculture and Forestry, Viet Nam WEBSITE https://www.apn-gcr.org/?p=4562

\section{Increased working knowledge on developing bankable climate proposals sheds light on adaptation measures}

Northeastern Thailand relies heavily on agriculture and inland capture fisheries. These sectors will be severely affected by the impacts of climate change and, therefore, appropriate adaptation measures to address these impacts are necessary, including tapping into climate adaptation finance sources.

The project conducted a five-day training programme to build the capacities of mainly government officials in developing bankable climate adaptation project proposals in line with national policies and plans. As the first step, the project conducted a mapping exercise of stakeholders involved in projects related to climate change to measure their interest in a training programme. Separately, an application portal was created to call for applicants, which also asked respondents on their experiences in conducting projects related to climate change and developing proposals.

Subsequently, the project conducted a training programme with the participation of 23 trainees representing academia and civil society organizations, three observers from international development agencies and eight resource persons from APN, Embassy of Canada in Thailand and the Food and Agriculture Organization, etc. The programme consisted of presentations, plenary discussions and group work that evolved around a five-step exercise: (1) mapping out climate drivers; (2) identifying the core problem and peripheral issues; (3) converting identified issues into project objectives; (4) developing a formal project structure; and (5) next steps leading to developing bankable proposals.
Consequently, the participants developed four concept notes. Additionally, a post-training evaluation showed increased working knowledge among the trainees in developing early-stage project proposals and enhanced understanding of the concept of climate rationale that is central to accessing climate adaptation finance sources.

PROJECT Capacity building programme on developing project proposals for climate change adaptation for northeast Thailand PROGRAMME Scientific Capacity Development (CAPaBLE) PROJECT LEADER Mr Lyan Baybay Villacorta, Asian Institute of Technology, Thailand ORGANIZATIONS INVOLVED Stockholm Environment Institute, Sweden; Food and Agriculture Organization of the United Nations; Regional Resource Centre for Asia and the Pacific, Thailand WEBSITE https://www.apn-gcr. $\operatorname{org} / \mathrm{p}=4595$ 


\section{Events}
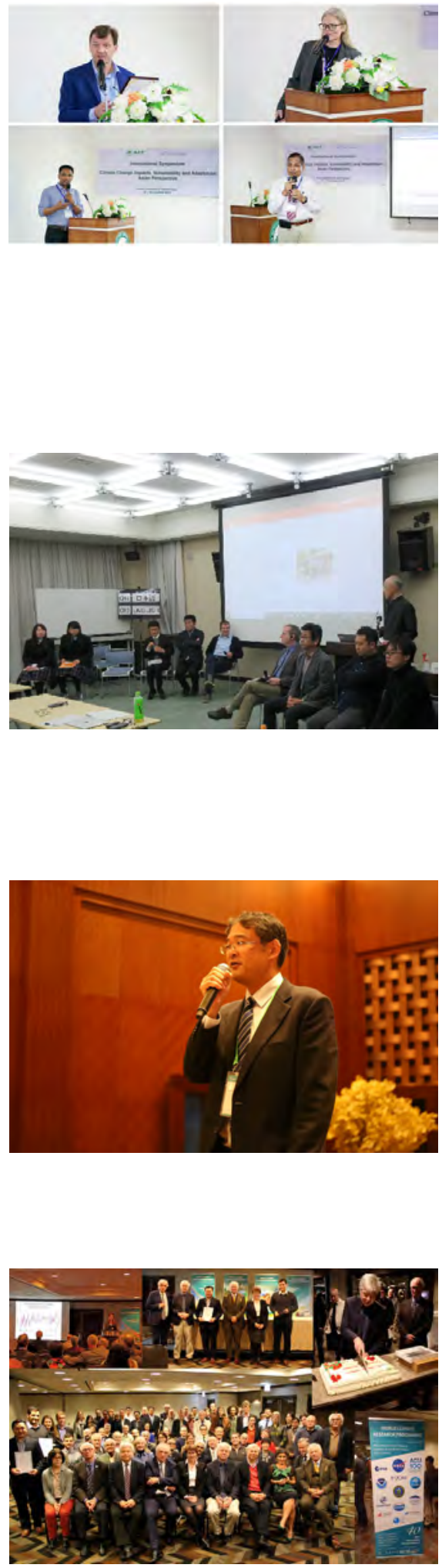

\section{WCRP 40th Anniversary}

In December 2019, APN was invited to participate at the World Climate Research Programme (WCRP) 40th Anniversary Symposium in the United States of America. Mr Gen'ichiro Tsukada, Director of the Secretariat, introduced the contribution of APN to the objectives of WCRP through the implementation of policy-relevant research and capacity development projects in the Asia-Pacific region.

\section{G20 Adaptation Workshop}

In June 2020, Mr Gen'ichiro Tsukada, Director of the Secretariat, was invited to participate at the G20 Workshop on the Synergy between Adaptation and Mitigation, hosted by the Government of Saudi Arabia. Mr Tsukada, as one of the resource persons, presented on the contribution of APN to the adaptation-mitigation synergy and the Circular Carbon Economy (CCE) by introducing APN-funded projects on waste management. Points discussed at the workshop included the importance of promoting measures that have adaptation-mitigation linkages, and introducing measures on CCE that also contribute to the increased promotion of adaptation-mitigation linkages. It was also agreed that there are two viewpoints of the linkages, which are adaptation to mitigation linkages for decreased vulnerability, and mitigation to adaptation linkages for enhanced resilience. 


\section{APPROVED PROJECTS}

Understanding the interaction of ocean acidification and marine tourism for sustainable management of coral reefs • Prof. Kirsten Benkendorff, Southern Cross University, Australia

Climate change, ageing and disability: Life experience of being old, disabled and affected by climate-induced disasters in China - Dr Joseph Balikuddembe, Sichuan University, China

ICRC CORDEX 2019: Promoting involvement of early-career scientists from the Asia-Pacific region in regional integrated and sustainable development through active participation and networking • Dr Shuyu Wang, Nanjing University, China

Developing capacity for post-typhoon disaster waste management in coastal cities in China, Fiji, and the Philippines • Dr Glenn Fernandez, Sichuan University, China

Facilitating the attendance, interaction and training of young and developing nation scientists from Asia-Pacific at the WCRP Institute of Advanced Studies in Climate Extremes and Risk Management - Prof. Zhihong Jiang, Nanjing University of Information Science and Technology, China

Integrated coastal landscape management: An adaptation related to climate change impact • Dr Dewayany Sutrisno, Indonesian Society for Remote Sensing, Indonesia

Building capacity to enhance farmer's capabilities to address the challenges of climate change using climate smart agriculture (CSA) strategies • Dr Nutan Kaushik, Amity University Uttar Pradesh, India

Strengthening adaptive capacities of South Asian agrarian communities by developing a Climate Information Network (CIN)-based scientific cropping calendar towards preparedness for weather extremes

\section{COMPLETED PROJECTS}

Climate smart actions "Saung Iklim" for small holders' farmers in Subang District - West Java Indonesia • Dr Perdinan, Bogor Agricultural University, Indonesia

Integrating health into urban planning towards sustainable development goals in developing countries - Dr Soo Chen Kwan, Kyoto University, Japan

Strengthening inter-sectoral coordination and governance for the effective implementation of Nepal's NDCs based on a voluntary national quality-of-governance standard for forest sector activities and programmes - Dr Federico Lopez-Casero, Institute for Global Environmental Strategies, Japan

Effective models for payment mechanisms for forest ecosystem services in Papua New Guinea, Philippines and Thailand - Dr Jintana Kawasaki, Institute for Global Environmental Strategies, Japan

Ecological vulnerability assessment for adaptation strategy formulation at different
- Dr Udita Ghosh Sarkar, South Asian Forum for Environment, India

Socio-hydrological perspective of climate change adaptation in large riverine islands: Comparative study from India, Bangladesh and Viet Nam • Dr Pankaj Kumar, Institute of Global Environmental Strategies, Japan

Assessment of the actual and potential contributions of smart city projects to climate resilience in selected Asia-Pacific cities - Dr Ayyoob Sharifi, Hiroshima University, Japan

Interlinkage of ecosystem services and human wellbeing to enhance climate smart landscapes in small watersheds: analysis for policy-relevant solutions in South Asian context - Dr Shamik Chakraborty, Hosei University, Japan

Search of unidentified organic markers in PM2.5 and PM2.5 source apportionment in major cities of Southeast Asia • Dr Keiichi Sato, Asia Center for Air Pollution Research, Japan

Collaborative research platform to manage risk and enhance resilience of coral reefs in Southeast Asia • Dr Rajendra Khanal, Tokyo Institute of Technology, Japan

Future water resources, their quality management and nutrient flux in Asian coastal megacities - Prof. Shin-ichi Onodera, Hiroshima University, Japan

Establishment of rainwater harvesting technology in selected upland farming communities in the Philippines • Ms Leila Landicho, University of the Philippines Los Baños, Philippines

Identification and up-scaling of climatesmart agriculture (CSA) practices for sustainable food security in high altitude farming regions of Himalaya - Dr Muhammad
Abid, Centre for Climate Research and Development, Pakistan

Pathways to strengthening capabilities for climate smart agriculture (CSA) in Pakistan - Dr Haroon Khan, University of Agriculture, Peshawar, Pakistan

International workshop on key indicator species and habitats for marine biodiversity change in East Asia • Prof. Kwang-Sik Choi, Jeju National University, Republic of Korea

Exploring gendered knowledge and inclusiveness in community resilience for flooding disaster. Case studies in Can Tho City (Viet Nam) and Cebu City (Philippines) - Mr Van Thai Nguyen, An Giang University, Viet Nam

Establishing a regional dataset on emerging pollutants to support surface water management of seven large cities of East and Southeast Asia • Dr Thi Phuong Quynh Le, Viet Nam Academy of Science and Technology, Viet Nam

Integrated approach of in situ measurement, modelling techniques, and advanced satellite remote sensing for mapping and quantifying contribution of local and regional biomass burning sources to air pollution in Southeast Asian countries • Dr Duc Luong Nguyen, National University of Civil Engineering, Viet Nam

Creating a conflict management model as a tool for sustainable community-based tourism (CBT) development in protected areas in Central, Viet Nam: Lessons from experience in Japan - Mr Ha Dung Hoang, Hue University of Agriculture and Forestry, Viet Nam

Enhancing capacity for public communities in renewable energy producing from livestock wastes adapting climate change - Dr Thu Nga Do, Electric Power University, Viet Nam spatial scales in Western Mongolia and China • Dr Suvdantsetseg Balt, Khovd State University, Mongolia

Climatogenic transformation of the Alpine landscapes in Mongolian and Siberian Altai - Dr Otgonbayar Demberel, Khovd University, Mongolia

Sustainable mangrove rehabilitation for global and local benefits - Prof. Leni D. Camacho, University of the Philippines Los Baños, Philippines

Anthropogenic perturbations to carbon export and greenhouse gas evasion from Asian river systems - Prof. Ji-Hyung Park, Ewha Womans University, Republic of Korea

Policy gaps and needs analysis for the implementation of NDCs on adaptation, and loss and damage in Bangladesh, Nepal and Sri Lanka • Ms Vositha Wijenayake, SLYCAN Trust, Sri Lanka

Identification of the best agricultural management practices with better greenhouse gas benefits in salinity-affected areas of South Asia - Dr Erandathie Lokupitiya, University of Colombo, Sri Lanka

Developing climate inclusive potential loss and damage assessment methodology for flood hazards • Dr Senaka Basnayake, Asian Disaster Preparedness Centre (ADPC), Thailand

Capacity building programme on developing project proposals for climate change adaptation for Northeast Thailand $\cdot \mathrm{Mr}$ Lyan Baybay Villacorta, Asian Institute of Technology, Thailand

Consumer perception of food safety risk and its impact on the willingness to pay for organic food in Southeast Asia • Dr Thich Nguyen Van, Banking University - Ho Chi Minh City, Viet Nam

Using indigenous knowledge to enhance community resilience to climate change in mountainous region of Viet $\mathrm{Nam}$ - Dr Ho Ngoc Son, Agriculture and Forestry Research and Development Centre for Mountainous Region (ADC), Viet Nam 


\section{Finances}

APN receives financial contributions

from: The Ministry of the Environment, Japan; Hyogo Prefectural Government, Japan; Ministry of Environment, Republic of Korea; and The Ministry for the Environment, New Zealand. In addition to direct financial contributions, APN receives significant in-kind contributions from member countries, in particular the Hyogo Prefectural Government, Japan.

The figures include executed expenditures for old and new projects and activities, as well as committed resources for multi-year projects.
FINANCIAL RESOURCES OF FY 2019 (USD)

\begin{tabular}{lrr}
\hline & \multicolumn{1}{l}{ Ministry of the Environment, Japan } & $1,792,000$ \\
\cline { 2 - 3 } $\begin{array}{l}\text { Donor contributions } \\
\text { FY } 2019\end{array}$ & Hyogo Prefectural Government, Japan & 187,000 \\
\cline { 2 - 3 } & Ministry of Environment, Republic of Korea & 43,000 \\
\cline { 2 - 3 } & Ministry for the Environment, New Zealand & 20,000 \\
\hline $\begin{array}{l}\text { Balance brought forward from FY 2018 } \\
\text { (including committed funds for multi-year projects) }\end{array}$ & 874,152 \\
\hline Returned funds from completed projects and adjustments & 593,174 \\
\hline \hline
\end{tabular}

USE OF RESOURCES IN FY 2019 (USD)

Executed and committed *

\begin{tabular}{|c|c|}
\hline Core programmes & $2,035,014$ \\
\hline Frameworks & 72,379 \\
\hline Other scientific and policy activities & 232,267 \\
\hline Institutional activities & 241,193 \\
\hline Personnel, administration and operational costs & 579,879 \\
\hline & $3,160,732$ \\
\hline
\end{tabular}

\section{NATIONAL FOCAL POINTS}

\section{BANGLADESH}

Billal Hossain

Ministry of Environment, Forest

and Climate Change

\section{BHUTAN}

Tenzin Khorlo

National Environment

Commission

\section{CAMBODIA}

Roath Sith

Ministry of Environment

FIJI

Vineil Narayan

Ministry of Economy

INDIA

J. R. Bhatt

Ministry of Environment, Forest and Climate Change

\section{INDONESIA}

Henri Bastaman

Ministry of Environment and Forestry

JAPAN

Eri Nakajima

Ministry of the Environment

LAO PEOPLE'S DEMOCRATIC REPUBLIC

Virasack Chundara

Ministry of Natural Resources

and Environment

MALAYSIA

Jailan Simon

Ministry of Energy, Science,

Technology, Environment and

Climate Change

MONGOLIA

Bayarbat Dashzeveg

Ministry of Environment and

Tourism
NEPAL

Radha Wagle

Ministry of Forests and

Environment

\section{NEW ZEALAND}

Douglas Hill

University of Otago

\section{PAKISTAN}

Muhammad Irfan Tariq

Ministry of Climate Change

PHILIPPINES

Marcial C. Amaro Jr.

Department of Environment and

Natural Resources

REPUBLIC OF KOREA

Myong Hwan Kim

Ministry of Environment

\section{RUSSIAN FEDERATION}

Andrey V. Adrianov

Russian Academy of Sciences

SRI LANKA

Anil Jasinghe

Ministry of Environment

\section{THAILAND}

Monthip Sriratana

National Research Council of

Thailand

UNITED STATES OF AMERICA

Luis M. Tupas

United States Department of Agriculture

\section{VIET NAM}

Ngo Tuan Dung

Ministry of Natural Resources and Environment

\section{SCIENTIFIC PLANNING GROUP MEMBERS}

\section{BANGLADESH}

Md. Giashuddin Miah

Bangabandhu Sheikh Mujibur

Rahman Agricultural University

\section{BHUTAN}

Norbu Gyeltshen

Royal University of Bhutan

CHINA

Wenjie Dong

Sun Yat-Sen University

FIJI

Awnesh Singh

The University of the South Pacific

INDIA

Hemant Borgaonkar

Indian Institute of Tropical

Meteorology
INDONESIA

Erna Sri Adiningsih

National Institute of Aeronautics and Space

\section{JAPAN}

Kensuke Fukushi

The University of Tokyo

LAO PEOPLE'S DEMOCRATIC REPUBLIC

Virasith Phomsouvanh

Ministry of Natural Resources

and Environment

\section{MALAYSIA}

Fariza Yunus

Malaysian Meteorological

Department

\section{MONGOLIA}

Tsogtbaatar Jamsran

Mongolian Academy of Sciences (retired)
NEPAL

Madan Lall Shrestha

Nepal Academy of Science and

Technology

\section{NEW ZEALAND}

Douglas Hill

University of Otago

PHILIPPINES

Henry Adornado

Department of Environment and

Natural Resources

REPUBLIC OF KOREA

Soojeong Myeong

Korea Environment Institute

RUSSIAN FEDERATION

Alexander Sterin

All-Russia Research Institute

of Hydrometeorological

Information-World Data Centre

\section{SRI LANKA}

Athula Karunanayake

Department of Meteorology

\section{THAILAND}

Jariya Boonjawat

Chulalongkorn University

\section{UNITED STATES OF AMERICA}

Luis M. Tupas

United States Department of

Agriculture

\section{VIET NAM}

Kim Chi Ngo

Vietnam Academy of Science

and Technology

\section{INVITED EXPERTS}

\section{Lance Clive Heath}

FreeLance Solutions, Australia

Ailikun

Chinese Academy of Sciences,

China
Kanayathu Chacko Koshy

Environmental Resources

Research Centre, India

Subramaniam Moten

Malaysia Meteorological

Department (retired), Malaysia
W. Andrew Matthews

New Zealand National

Commission for UNESCO

(retired), New Zealand

Juan Pulhin

University of the Philippines

Los Baños, Philippines 
